Document downloaded from:

http://hdl.handle.net/10251/48418

This paper must be cited as:

Balart Gimeno, JF.; Fombuena Borrás, V.; Boronat Vitoria, T.; Reig Pérez, MJ.; Balart Gimeno, RA. (2012). Surface modification of polypropylene substrates by UV photografting of methyl methacrylate (MMA) for improved surface wettability. Journal of Materials Science. 47(5):2375-2383. doi:10.1007/s10853-011-6056-9.

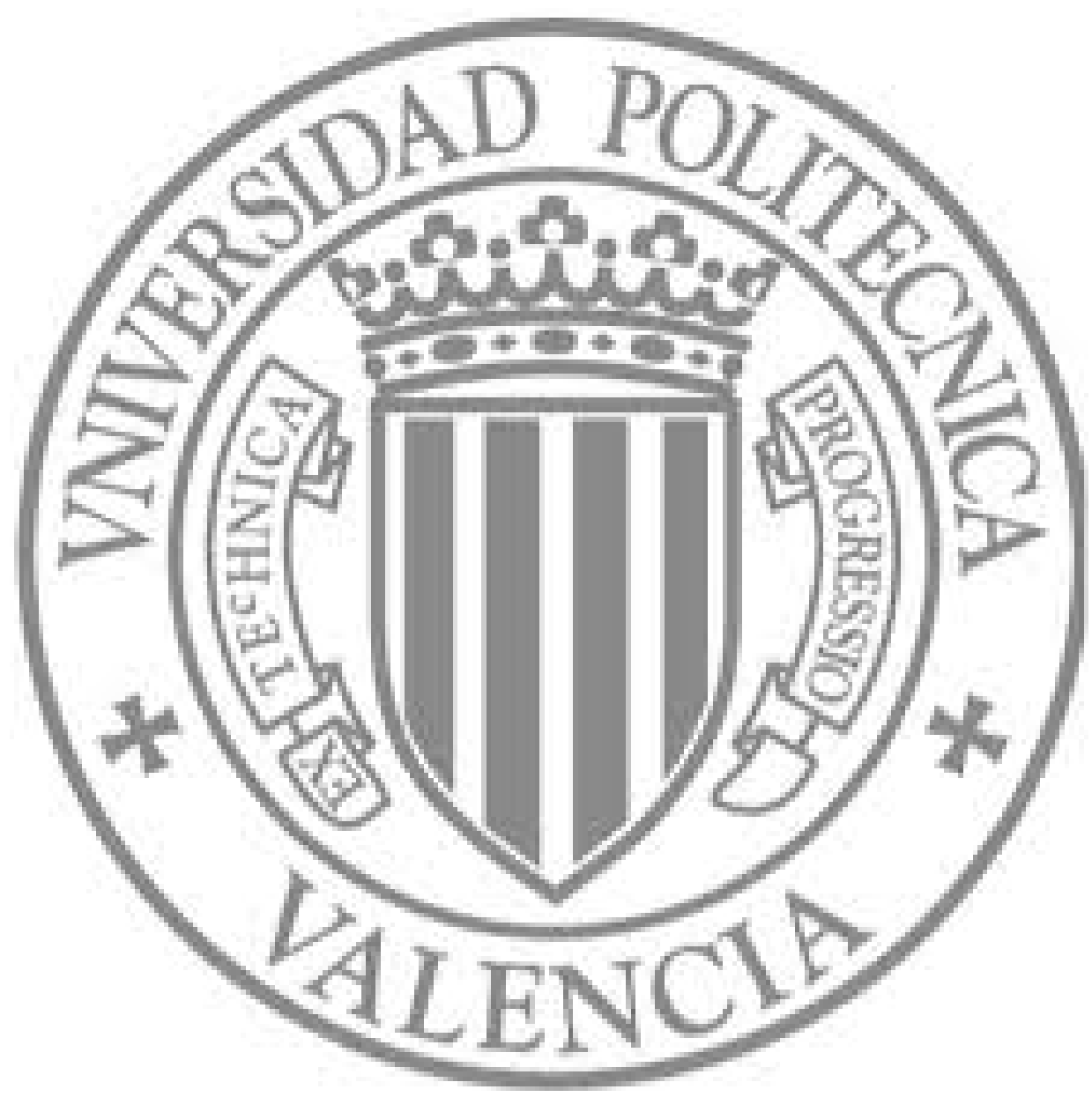

The final publication is available at

http://dx.doi.org/10.1007/s10853-011-6056-9

Copyright

Springer Verlag (Germany) 


\title{
Surface modification of polypropylene substrates by UV photografting of methyl methacrylate (MMA) for improved surface wettability
}

\author{
J. Balart, V. Fombuena, T. Boronat, M.J. Reig, R. Balart \\ Materials Technology Institute (ITM), Polytechnic University of Valencia, Plaza \\ Ferrandiz y Carbonell s/n,03801, Alcoy (Alicante), Spain
}

\begin{abstract}
Despite polypropylene is one of the most used commodity plastics, its adhesion properties are remarkably restricted by its non-polar nature which leads to low wetting properties and, consequently, poor adhesion behavior. We report the use of ultraviolet photografting process of methyl methacrylate (MMA) monomer as an efficient chemical treatment for surface activation of polypropylene. Contact angle measurements are used for evaluating changes in polypropylene wetting properties together with surface free energy calculations. Chemical changes are showed in terms of the exposure time to UV radiation. Scanning electron microscopy (SEM) has been used to evaluate topography changes in a qualitative way; atomic force microscopy (AFF) has been used for a quantitative evaluation of surface changes in terms of roughness. The use of Fourier transformed infrared spectroscopy (FTIR) has revealed the nature of the chemical changes induced by the photografting process of MMA.
\end{abstract}

Keywords: photopolymerization, poly(propylene) (PP), surface modification, functionalization of polymers. 


\section{Introduction.}

Polypropylene is one of the most used commodity plastics as a consequence of a good balance between properties (mechanical, thermal, chemical, processing, etc.) and cost. From a chemical point of view, it shows high inertness due to its non-polar nature and this leads to a hydrophobic polymer characterized by very low wetting properties. This fact is mainly responsible for problems in adhesion, painting, coating, etc. So that, the use of polypropylene in these applications requires a surface pre-treatment in order to improve its intrinsically low wetting properties. This can be achieved by insertion of polar groups and promoting changes in surface topography.

It is possible to modify the bulk properties of polymers by blending with different polymers or using reactive extrusion processes with the aid of compatibilizing agents. Blends of polypropylene with polar polymers such as ethylene-acrylic acid are useful to obtain a remarkable increase in hydrophilic behavior and this contributes to improve adhesion properties.[1] Nevertheless, surface modifications are preferable for surface adhesion. There are several chemical and physical processes for surface modification. Physical processes as plasma technologies [2-4] (corona, low pressure, atmospheric plasma, etc.) are very useful to achieve good functionalization levels together with interesting changes in surface roughness, but it is important to remark that these techniques are still expensive. On other hand, chemical processes are characterized by easy implementation and low cost and the overall effects are similar to those obtained with plasma processes. Some of these chemical processes are based on the use of strong acids or alkalis to promote surface activation and/or changes in surface roughness. In addition to the use of these aggressive chemicals, it is possible to achieve surface activation of a wide variety of monomers by interlocking of polar groups on polypropylene chains and this fact, will also promote changes in surface roughness. 
This can be carried out by using a UV induced grafting process [5-8]. This requires the use of a base monomer, such as acrylic, which can be activated by UV radiation in the presence of a free radical photoinitiator which decomposes rapidly [9]. The action of UV light leads the photoinitiator to an excited state which needs hydrogen to form stable free radicals (Scheme 1).

\section{Scheme 1}

Then hydrogen abstraction from the topmost layers of the polymer occurs thus leading to formation of interlock points in which, monomer can be chemically bonded by addition processes. These free radicals derived from photoinitiator and polymer chains at the topmost surface layers can react with the acrylic monomer to form typical species of an addition process as indicated in Scheme 2 so that, new radicals are formed. Addition processes continue until termination occurs. After termination, some macroradical are chemically grafted to the topmost layers of the polymer surface and also, some non-grafted olygomers can be obtained (Scheme 3). These olygomers must be removed by cleaning surfaces after the UV grafting process.

\section{Scheme 2}

\section{Scheme 3}

In a typical photografting process, the monomer is dissolved in a carrier solvent such as acetone, benzene, chloroform, methanol, etc. together with the appropriate amount of the photoinitiator. Some authors have used these processes to modify filtration properties on analytical membranes. [10-14]. Other research works have 
focused on the use of UV photografting processes as coating for electrolytic copper. [15] Photografting processes with different base monomers have been successfully used to improve hydrophilic nature of electroactive polymers such as polyaniline and in some cases, self-protonated surfaces are obtained thus having a positive effect on surface conductivity.[16]

The photografting process can be carried out in a single stage or in a double step process $[7,17]$. The use of a single stage process is preferable since it lowers the working time which is a key factor for industrial applications. In this, the polymer surface is exposed to UV radiation in the presence of a solution containing both monomer and photoinitiator. The use of different photoinitiators such as benzophenone (BP) [18], methylbenzoylformate (MBF), xanthone, etc. has been reported with excellent results since all of them show absorption peaks in the UV range. With respect to solvent, it is important to remark that it must be appropriately selected to ensure good solubility of both the photoinitiator and the monomer. The most commonly used solvents are acetone, methanol, chloroform, carbon tetrachloride, cyclohexane, cyclohexanone, ethyl acetate, tetrahydrofuran, etc. and mixtures, depending on the monomer and/or the photoinitiator. [19, 20] Some results about the optimum photoinitiator/monomer ratio with several solvents have been reported and they have great influence on final grafting of the monomer on the polymer surface.

Regarding the use of monomers, a wide variety of compounds have been used by different authors with different purposes. Some monomers such as polyacrylamide (PAAm) [21], polyacrylic acid (PAA) [21], vinyl acetate (VAc) [22-24], etc. are used to improve and/or control wettability on chemically inert polymers for improved adhesion, as we have reported in our previous works with acrylic acid (AA) [25] and methyl methacrylate [25]. Trimethylolpropane triacrylate has been used to provide good 
thermal degradation resistance [26] and 1,6-hexanediol diacrylate to enhance mechanical and physical properties of jute fibers [27]. Different acrylic monomers have been used to improve interface phenomena between the polymeric matrix and reinforcements in composite materials.[28, 29] The use of other hydrophobic monomers can lead to super-hydrophobic properties for self-cleaning materials. For example, polyacrylic acid (PAA) can be grafted onto Nylon-6 fibers to form PAA hydrogels which are useful to avoid seaweeds' adhesion on fishnets. [30] Some works have reported the usefulness of polyvinylpyrrolidone-iodine to provide antibacterial properties on polymer substrates [31]; different kinetic studies on grafting isobornyl acrylate have been carried out as this monomer is suitable as coating for digital HDDVD [32, 33].

In this work we have used a one-step UV photopolymerization process of methyl methacrylate (MMA) monomer in presence on benzophenone (BP) as photoinitiator on an acetone solution to increase the low intrinsic wettability of polypropylene sheets in order to provide good wetting properties for different technological processes such as adhesive bonding, painting, etc. The influence of the exposure time to UV radiation has been evaluated and the overall changes in surface wettability have been studied by contact angle measurements and subsequent free energy calculation. A qualitative analysis of surface changes has been carried by using scanning electron microscopy (SEM) and quantitative information has been determined by using atomic force microscopy (AFM). Chemical changes derived from the surface pre-treatment have been followed by FTIR-ATR.

\section{2.- Experimental}




\section{1.- Materials.}

Photografting process was carried out on a polypropylene commercial grade ISPLEN ® PB 180 G2M provided by Repsol YPF (Repsol, Madrid, Spain). This is a heterophase copolymer with high fluency which is appropriate for injection molding with a flow rate of $20 \mathrm{~g} / 10 \mathrm{~min}$ and a density of $0.905 \mathrm{~g} / \mathrm{cm}^{3}$. Sheets sizing $160 \times 60 \times 2.2$ $\mathrm{mm}^{3}$ were injection molded at a temperature of $230{ }^{\circ} \mathrm{C}$ with a Mateu\&Sole, model Meteor 270/75 (Mateu\&Sole, S.A., Barcelona, Spain). After injection molding, samples sizing $10 \times 10 \mathrm{~mm}^{2}$ were cut with a hydraulic press Melchor Gabilondo, model KCK15A (Melchor Gabilondo S.A., Vizcaya, Spain). These samples were washed in double distilled water to remove impurities and then they were stored in a vacuum desiccator.

As a base monomer for surface modification, stabilized methyl methacrylate (MMA) monomer with a purity of $99 \%$ was used (Acros Organics, Geel, Belgium). The selected photoinitiator was benzophenone (BP) supplied by Scharlau Chemie S.A. (Scharlab S.L., Barcelona, Spain). Both monomer and photoinitiator were dissolved in laboratory grade acetone (Aurelio Crespo Sospedra, C.B. Alfafar, Valencia, Spain) to obtain the base solution for UV photografting process with a MMA:acetone volume ratio of 1:4. After this, 5 weight $\%$ of benzophenone was added.

\section{2.- Photopolymerization process.}

A pressure mercury lamp (1000 $\mathrm{W}$ and $350 \mathrm{~nm}$ by wavenumber) mounted on a UVASPOT 1000RF2 supplied by Honle UV Technology (Honle Spain, S.A., Barcelona, Spain) was used for surface modification.

In a first step samples sizing $10 \times 10 \mathrm{~mm}^{2}$ are placed in a Petri dish and fully covered by the solution containing MMA monomer and benzophenone. Then the Petri dish is covered with a glass lid to guarantee invariable atmosphere conditions avoiding 
gas emanation. After this, the Petri dish was placed on aluminium rack which is located at a fixed distance of $25 \mathrm{~cm}$ below the mercury lamp. The exposure time to UV radiation was varied between 30 up to $240 \mathrm{~s}$ and after exposure to UV radiation samples were washed with distilled water to remove non-grafted monomer, olygomers and volatiles and, finally, dried at room temperature in a vacuum desiccator.

\section{3.- Wettability characterization and surface free energy calculation.}

Contact angle measurements were carried out with a EasyDrop Standard goniometer model FM140 (KRÜSS GmbH, Hamburg, Deutschland) which is equipped with a video capture kit and analysis software (Drop Shape Analysis SW21; DSA1). Four different test liquids were used as test liquids: diiodomethane (stabilized, >99\% purity) supplied by Acros Organics (Acros Organics, Geel, Belgium), formamide (reagent grade ACS), and glycerol (> 99\% purity) supplied by Scharlau Chemie S.A. (Scharlab S.L., Barcelona, Spain) and double distilled water. At least ten measurements were carried out for each sample and average values were calculated. The maximum error did not exceed 3\%. Surface free energy values were calculated using the OwensWendt method which takes into account the dispersive (non-polar) and polar contribution to the total surface free energy value.[25]

\section{4.- Surface morphology.}

Surface morphology of low density polyethylene sheets pre-treated with UV photografting process were evaluated with a scanning electron microscope SEM, supplied by FEI, model PHENOM (FEI Company, Eindhoven, The Netherlands), with an accelerating voltage of $5 \mathrm{KV}$. Samples were covered with a gold-palladium alloy in a Sputter Coater EMITECH mod. SC7620 (Quorum Technologies Ltd, East Sussex, UK). 
Micro-scale roughness study was carried out with a portable surface roughness tester Surftest SJ-301 (Mitutoyo, Hampshire, United Kingdom) with a profile filter $\lambda \mathrm{c}$ of $0.8 \mathrm{~mm}$ and average roughness $(\mathrm{Ra})$ and height of average roughness $(\mathrm{Rz})$ were calculated for a total length of $3.2 \mathrm{~mm}$.

Surface topography changes were evaluated with atomic force microscopy (AFM) using a Multimode AFM microscope with a Nanoscope IIIa ADCS controller (Veeco Metrology Group, Cambridge, UK). A monolithic silicon cantilever Nano World Point-robe ${ }^{\circledR}(\mathrm{NCH})$ with a force constant of $42 \mathrm{~N} \mathrm{~m}^{-1}$ and a resonance frequency of $320 \mathrm{~Hz}$ was used to work on the tapping mode.

\section{5.- Characterization of chemical changes.}

Chemical changes produced by the surface pre-treatment by photopolymerization were studied using Fourier transformed infrared spectroscopy (FTIR) with attenuated total reflectance (ATR) accessory. The FTIR spectrometer was a Perkin Elmer, mod FTIR Spectrum BX (PerkinElmer España, S.L., Madrid, Spain) and the ATR accessory model was MIRacle supplied by Pike Technologies (PIKE Technologies, Inc. , Madison , USA). Samples were directly placed in the ATR accessory and 10 scans were performed in the $4000-800 \mathrm{~cm}^{-1}$ wavenumber range with a resolution of $2 \mathrm{~cm}^{-1}$.

\section{3.- Results and discussion.}

\section{1.- Characterization of wettability and chemical changes.}

Surface changes due to methyl methacrylate photopolymerization were followed by contact angle measurements with different test liquids. Figure 1 shows a plot 
evolution of the static contact angle of polypropylene using different test liquids in terms of the exposure time to UV radiation in presence of the monomer solution and photoinitiator. We can observe a remarkable decrease in contact angle values for all the test liquids. In the case of water a test liquid, the initial contact angle of untreated polypropylene is about $100^{\circ}$. We can see that this contact angle is considerably reduced up to values of about $47^{\circ}$ for an exposure time of $90 \mathrm{~s}$. As the exposure time increases over $90 \mathrm{~s}$, the contact angle follows similar tendency but more slightly up to values close to $40^{\circ}$ for exposure times of about $210 \mathrm{~s}$. Similar tendency can be seen with the other three test liquids. Regarding glycerol as test liquid, an initial decrease in contact angle values is detected for exposure times of $90 \mathrm{~s}$ and once reached this time, the decrease in contact angle is less pronounced. With respect to the use of diiodomethane as test liquid, the initial contact angle, located at $54^{\circ}$, is rapidly decreased up to values of $37^{\circ}$ for an exposure time of $30 \mathrm{~s}$ and after this, a slight decrease up to values of $30^{\circ}$ for exposure times in the 120 - $180 \mathrm{~s}$ range is observed. Finally, the initial contact angle of formamide, located at $71.4^{\circ}$ is remarkably decreased up to values of about $47^{\circ}$ for an exposure time of $30 \mathrm{~s}$ and a slight decreasing tendency is observe with increasing times. It is important to remark that the surface pre-treatment with MMA does not lead to total wettability (in the exposure time range evaluated in this research work), since contact angles for all liquids remain at values higher that $0^{\circ}$, but a great decrease is obtained for the four test liquids as observed in Figure 1 and this would have a positive effect on wetting properties of polypropylene substrates.

\section{Figure 1}


As we have described previously, the use of four different test liquids allows the

\section{Table 1}

FTIR is a useful technique to evaluate chemical changes in the topmost layers as a consequence of methyl methacrylate photografting on polypropylene surface. As we 
have described previously, presence of an initiator and subsequent exposure to UV radiation, leads to formation of interlock points in which, activated MMA monomers can be chemically bonded to polypropylene chains; so that, the grafted monomer is not lost after washing.

\section{Figure 2}

Figure 2 shows a comparative plot of the FTIR-ATR spectra for different polypropylene surfaces subjected to different exposure times to MMA photografting. As we can observe, treated samples show presence of different peaks and bands that do not appear in the untreated polypropylene surface. These peaks are directly related to presence of interlocked methyl methacrylate monomers on top most layers. Presence of $-\mathrm{C}=\mathrm{O}$ species can be detected in the pre-treated samples as different typical absorption peaks can be seen at $1649 \mathrm{~cm}^{-1}$ and $1729 \mathrm{~cm}^{-1}$. In addition, presence of ester groups is evident from the presence of different absorption peaks located at $1274 \mathrm{~cm}^{-1}, 636 \mathrm{~cm}^{-1}$ and $1195 \mathrm{~cm}^{-1}$, the last one corresponding to the $\mathrm{O}-\mathrm{CH}_{3}$ group. Furthermore, the appearance of different peaks in the untreated polypropylene surface changes as the exposure time to MMA photografting increases and this is related to surface chemical changes due to chemical bonding of MMA monomers onto polypropylene surface. Thus, the peak located at $1439 \mathrm{~cm}^{-1}$, which corresponds to $\mathrm{CH} 3$ changes in a remarkable way due to anchorage or MMA groups. [34]

\section{2.- Characterization of surface morphology.}

To analyze the surface changes of polypropylene samples treated with UV photografting process of methyl methacrylate, scanning electron microscopy (SEM) 
was used. Figure 3 shows the microphographs of polypropylene with different exposure times to UV radiation in presence of MMA monomer together with the corresponding water contact angle photograph.

\section{Figure 3}

The microphotograph for the untreated PP (Figure 3a) is characterized by a very smooth surface, free of any roughness; thus the initial water contact angle is high, around $87.3^{\circ}$. As the exposure time to UV photografting increases, we observe remarkable changes in surface topography. So that, polypropylene subjected to UV photopolymerization process with an exposure time of $180 \mathrm{~s}$ (Fig. 3d) presents a very rough surface, with large differences in height between the peaks and valleys. This roughness is closely related to the increase in surface energy produced as a result of the deposition of a chemically bonded functionalized layer. SEM microphotographs with different exposure times (60 and $120 \mathrm{~s}$; Figure $3 \mathrm{~b}$ and $3 \mathrm{c}$ respectively) are also shown. In these cases, there is also a rough surface, but not as much as in the case of $180 \mathrm{~s}$. We observe rough surfaces but differences in height between peaks and valley seem to be lower. Also we can observe the importance of surface changes in overall wettability of polypropylene substrates as the water contact angle decreases with rougher surfaces together with presence of functionalized species chemically bonded to the top most layers.

In addition to this, a micro-roughness study has been done to evaluate changes in roughness values as a consequence of the UV photografting process. Fig. 4 shows a comparative plot of the roughness profiles obtained for untreated polypropylene and polypropylene surfaces with different exposure times to UV photografting process. We 
can observe in a clear way the tendency as the roughness is more pronounced for long exposure times to UV photografting process. These roughness profiles are in accordance with previous results regarding surface characterization by SEM techniques and changes in wetting properties as the main mechanisms responsible for the wettability improvement are surface functionalization by insertion of polar groups (derived from methyl methacrylate monomers) and changes in topography due to formation of a heterogeneous polymer layer in polypropylene surface. In addition to this qualitative information, Table 2 summarizes the main parameters regarding surface roughness for untreated and UV photografted polypropylene. The initial average roughness $(\mathrm{Ra})$ of untreated polypropylene is about $0.11 \mu \mathrm{m}$ and this value increases as the exposure time to UV photografting process increases and higher values of $\mathrm{Ra}$ are obtained for exposure times of $240 \mathrm{~s}$ ( $\mathrm{Ra}$ values of about $0.53 \mu \mathrm{m})$. In a similar way, the $\mathrm{Rz}$ values, representative for the height of the average roughness values, we observe an increasing tendency. So that, the initial $\mathrm{Rz}$ value for untreated polypropylene is close to $0.89 \mu \mathrm{m}$ and this increases up to $3.36 \mu \mathrm{m}$ for polypropylene surfaces with an exposure time to UV photografting process of $240 \mathrm{~s}$.

\section{Figure 4}

\section{Table 2}

As we have described before, the information provided by SEM analysis is and a complementary roughness study is useful to evaluate changes in topography due to the UV photografting process. In fact, the previous roughness study has revealed important changes in the micro-scale range. Nevertheless, due to the nature of the UV 
photografting process, it is interesting to obtain qualitative and quantitative information about surface topography and this information can be obtained by using atomic force microscopy (AFM). Figure 5 shows 3D representation of surface topography (20x20 $\mu \mathrm{m}^{2}$ ) for untreated PP surface (Figure 5a) and PP surface with different exposure times to UV photografting process in the $60-240 \mathrm{~s}$ range. The information obtained by AFM is similar to that obtained with the roughness study but a nano-scale range due to the sensitiveness of AFM in this measurement range. The AFM 3D representation of the untreated sample (Figure 5a), is characterized by very smooth surface. The $R_{\mathrm{rms}}$ value for this surface is about $50 \mathrm{~nm}$. We can observe that as the exposure time to UV photografting process increases, the overall roughness topography of PP surface also increases. For higher exposure times, around 240 seconds, the height difference between peaks and valleys is very pronounced.

\section{Figure 5}

The three-dimensional topography representation of untreated PP is very smooth if compared to the topography of PP with different exposure times to UV photografting. We can also observe the influence of the exposure time to UV in the overall topography representation. The longer is the exposure time, the rougher is the topography of the treated polypropylene surface. Tab. 3 shows the values of root mean squared roughness values $\left(\mathrm{R}_{\mathrm{rms}}\right)$ and maximum of all micrographs analyzed.

Table 3 
Roughness values for 0 -second exposure correspond to those in the untreated sample. The roughness values, both mean and maximum, show an upward trend with increasing exposure time. The $\mathrm{R}_{\mathrm{rms}}$ roughness value for untreated polypropylene is about $26.59 \mathrm{~nm}$, while PP surface with an exposure time of $240 \mathrm{~s}$ to UV photografting is close to $310.11 \mathrm{~nm}$ and this represents a remarkable increase in surface roughness. Thse results are in accordance with previous results obtained in the micro-scale roughness study and overall wetting changes.

\section{Conclusions.}

UV photografting of methyl methacrylate (MMA) monomer is an efficient technique to improve the low intrinsic wetting properties of polypropylene substrates. The increase in wettability is evident from the observation of the evolution of contact angles with different text liquids. In accordance with this, the total free surface energy increases from $31.5 \mathrm{~mJ} \mathrm{~m}^{-2}$ for untreated polypropylene up to values around $57.5 \mathrm{~mJ} \mathrm{~m}^{-2}$ for polypropylene substrates with an exposure time to UV photografting of $240 \mathrm{~s}$. It is important to remark that substantial changes are detected in the polar component of the total surface free energy which changes from $3.0 \mathrm{~mJ} \mathrm{~m}^{-2}$ for untreated polypropylene up to $26 \mathrm{~mJ} \mathrm{~m}^{-2}$ for exposure times in the $210-240 \mathrm{~s}$ range. The FTIR study has revealed presence of polar groups derived methyl methacrylate monomers which have been chemically bonded in the top most layers of polypropylene substrates and this is responsible for an increase in surface functionalization. On other hand, the SEM analysis has revealed qualitative changes in surface topography as the exposure time to UV photografting process increases. These changes have been quantified at a microand a nano-scale range by using conventional roughness study and AFM respectively. In both cases, a marked increasing tendency of average roughness values is obtained 
thus indicating that the improvement of polypropylene wetting properties is achieved by functionalization and changes in surface topography.

\section{Acknowledgements}

This work belongs to the project IPT-310000-2010-037,"ECOTEXCOMP: Research and development of textile structures useful as reinforcement of composite materials with marked ecological character." funded by the "Ministerio de Ciencia e Innovacion", with an aid of 189540.20 euros, within the "Plan Nacional de Investigación Científica, Desarrollo e Innovación Tecnológica 2008-2011” and funded by the European Union through FEDER funds, Technology Fund 2007-2013, Operational Programme on $\mathrm{R}+\mathrm{D}+\mathrm{i}$ for and on behalf of the companies."Also, microscopy services at UPV are acknowledged for SEM and AFM support. 


\section{References}

1. Novak, I. and S. Florian, Study of the change in polarity of polypropylene modified in bulk by polar copolymers. Journal of Materials Science, 2001. 36(20): p. 4863-4867.

2. Sanchis, M.R., et al., Surface modification of a polyurethane film by low pressure glow discharge oxygen plasma treatment. Journal of Applied Polymer Science, 2007. 105(3): p. 1077-1085.

3. Sanchis, R., et al., Improved adhesion of LDPE films to polyolefin foams for automotive industry using low-pressure plasma. International Journal of Adhesion and Adhesives, 2008. 28(8): p. 445-451.

4. Sanchis, R.M., et al., Enhancement of Wettability in low density polyethylene films using low pressure glow discharge N-2 plasma. Journal of Polymer Science Part B-Polymer Physics, 2007. 45(17): p. 2390-2399.

5. Deng, H.P. and W.T. Yang, Grafting copolymerization of styrene and maleic anhydride binary monomer systems induced by UV irradiation. European Polymer Journal, 2005. 41(11): p. 2685-2692.

6. Lisboa, P., et al., Surface functionalisation of polypyrrole films using UV light induced radical activation. Applied Surface Science, 2006. 252(13): p. 43974401.

7. Wang, Y.X., et al., Directly fabricating monolayer nanoparticles on a polymer surface by $U V$-Induced MMA/DVB microemulsion graft polymerization. Macromolecular Rapid Communications, 2005. 26(2): p. 87-92.

8. Xing, C.M., J.P. Deng, and W.T. Yang, Surface functionalization of polypropylene film via $U V$-induced photografting of $N$-vinylpyrrolidone/maleic 
anhydride binary monomers. Macromolecular Chemistry And Physics, 2005. 206(11): p. 1106-1113.

9. El Kholdi, O., et al., Modification of adhesive properties of a polyethylene film by photografting. Journal of Applied Polymer Science, 2004. 92(5): p. 28032811.

10. Piletsky, S.A., et al., Surface functionalization of porous polypropylene membranes with molecularly imprinted polymers by photograft copolymerization in water. Macromolecules, 2000. 33(8): p. 3092-3098.

11. Susanto, H. and M. Ulbricht, Photografted thin polymer hydrogel layers on PES ultrafiltration membranes: Characterization, stability, and influence on separation performance. Langmuir, 2007. 23(14): p. 7818-7830.

12. Ulbricht, M., Photograft-polymer-modified microporous membranes with environment-sensitive permeabilities. Reactive \& Functional Polymers, 1996. 31(2): p. 165-177.

13. Ulbricht, M., M. Riedel, and U. Marx, Novel photochemical surface functionalization of polysulfone ultrafiltration membranes for covalent immobilization of biomolecules. Journal Of Membrane Science, 1996. 120(2): p. 239-259.

14. Villagra Di Carlo, B., J. Carlos Gottifredi, and A. Claudio Habert, Synthesis and characterization of composite membrane by deposition of acrylic acid plasma polymer onto pre-treated polyethersulfone support. Journal of Materials Science, 2011. 46(6): p. 1850-1856.

15. Yang, G.H., et al., Surface graft copolymerization of poly(tetrafluoroethylene) films with $N$-containing vinyl monomers for the electroless plating of copper. Langmuir, 2001. 17(1): p. 211-218. 
16. Kang, E.T., et al., Surface modification and functionalization of electroactive polymer films via grafting of polyelectrolyte, polyampholyte and polymeric acids. Journal of Materials Science, 1996. 31(5): p. 1295-1301.

17. Zhu, J.W., et al., A facile method for grafting polymerisation of acrylonitrile onto LDPE film with high grafting efficiency. Macromolecular Chemistry And Physics, 2006. 207(1): p. 75-80.

18. Kong, L.B., J.P. Deng, and W.T. Yang, Detailed 1D/2D NMR analyses of benzophenone-related reaction products from a photopolymerization system of vinyl acetate and benzophenone. Macromolecular Chemistry And Physics, 2006. 207(24): p. 2311-2320.

19. Xing, C.M., J.P. Deng, and W.T. Yang, Surface photografting polymerization of binary monomers maleic anhydride and n-butyl vinyl ether on polypropylene film I. Effects of principal factors. Polymer Journal, 2002. 34(11): p. 801-808.

20. Xing, C.M., J.P. Deng, and W.T. Yang, Surface photografting polymerization of binary monomers maleic anhydride and n-butyl vinyl ether on polypropylene film II. Some mechanistical aspects. Polymer Journal, 2002. 34(11): p. 809-816.

21. Janorkar, A.V., A.T. Metters, and D.E. Hirt, Modification of poly(lactic acid) films: Enhanced wettability from surface-confined photografting and increased degradation rate due to an artifact of the photografting process. Macromolecules, 2004. 37(24): p. 9151-9159.

22. Tan, L., J.P. Deng, and W.T. Yang, A facile approach to surface graft vinyl acetate onto polyolefin articles. Polymers For Advanced Technologies, 2004. 15(9): p. 523-527.

23. Deng, J.P., W.T. Yang, and B. Ranby, Surface photografting polymerization of vinyl acetate (Vac), maleic anhydride (MAH), and their charge transfer complex 
(CTC). III. VAc(3). Journal of Applied Polymer Science, 2001. 80(9): p. 14261433.

24. Deng, J.P. and W.T. Yang, Surface photografting polymerization of vinyl acetate, maleic anhydride, and their charge-transfer complex. V. Chargetransfer complex (1). Journal of Applied Polymer Science, 2005. 95(4): p. 903909.

25. Balart, J., et al., Optimization of adhesion properties of polypropylene by surface modification using acrylic acid photografting. Journal of Applied Polymer Science, 2010. 116(6): p. 3256-3264.

26. Kaczmarek, H., Photopolymerization of trimethylolpropane triacrylate in a matrix of linear-polymers. Polimery, 1995. 40(6): p. 333-340.

27. Khan, M.A., S. Shehrzade, and M.M. Hassan, Effect of alkali and ultraviolet $(U V)$ radiation pretreatment on physical and mechanical properties of 1,6hexanediol diacrylate-grafted jute yarn by UV radiation. Journal of Applied Polymer Science, 2004. 92(1): p. 18-24.

28. Ganan, P. and I. Mondragon, Fique fiber-reinforced polyester composites: Effects of fiber surface treatments on mechanical behavior. Journal of Materials Science, 2004. 39(9): p. 3121-3128.

29. Maerder, E., et al., Adhesion of PBO fiber in epoxy composites. Journal of Materials Science, 2007. 42(19): p. 8047-8052.

30. Zhao, Y., et al., Preparation and properties of novel fishnet fibers with inhibitory effects on the adhesion of seaweeds. Journal of Materials Science, 2007. 42(19): p. 8287-8291. 
31. Xing, C.M., J.P. Deng, and W.T. Yang, Synthesis of antibacterial polypropylene film with surface immobilized polyvinylpyrrolidone-iodine complex. Journal of Applied Polymer Science, 2005. 97(5): p. 2026-2031.

32. Srilatha, T. and P.R. Rao, Graft polymerization of isobornyl acrylate and isobornyl methacrylate onto cis-polybutadiene - A kinetic study. Asian Journal of Chemistry, 2007. 19(5): p. 3755-3764.

33. Moon, J.H., et al., A study on UV-curable coatings for HD-DVD: Primer and top coats Progress in Organic Coatings, 2007. 59(2): p. 106-114.

34. Ramesh, S., et al., FTIR studies of PVC/PMMA blend based polymer electrolytes. Spectrochimica Acta Part a-Molecular and Biomolecular Spectroscopy, 2007. 66(4-5): p. 1237-1242. 


\section{Table captions}

Table 1.- Variation of total surface free energy $\left(\gamma_{s}\right)$ and its polar $\left(\gamma_{s}^{p}\right)$ and dispersive $\left(\gamma_{\mathrm{s}}^{\mathrm{d}}\right)$ contribution of polypropylene surface in terms of the exposure time to methyl methacrylate UV photografting.

Table 2.- Variation of average roughness (Ra) and height of average roughness (Rz) in terms of the exposure time to methyl methacrylate UV photografting.

Table 3.- Variation of root mean squared roughness (Rrms) and $\max \mathrm{Z}$ heigh obtained by AFM analysis in terms of the exposure time to methyl methacrylate UV photografting. 


\section{Figure legends}

Scheme 1.- Formation of free radicals on benzophenone photoinitiator by UV radiation followed by hydrogen abstraction on polymer chain.

Scheme 2.- Reaction of free radicals derived from photoinitiator and polymer chain with acrylic monomer by addition processes.

Scheme 3.- Termination stage of the photopolymerization process of polymer substrate in presence of photoinitiator and acrylic monomer.

Figure 1.- Evolution of the static contact angle in terms of the exposure time to methyl methacrylate UV photografting for different test liquids.

Figure 2.- FTIR-ATR spectra of polypropylene surface with different exposure times to methyl methacrylate UV photografting.

Figure 3.- SEM microphotographs (400x) and corresponding water contac angle photos for different exposure times to methyl methacrylate UV photografting, a) $0 \mathrm{~s}, \mathrm{~b}$ ) $60 \mathrm{~s}, \mathrm{c}$ ) $120 \mathrm{~s}$ and d) $180 \mathrm{~s}$.

Figure 4.- Comparative plot of the roughness profiles of polypropylene surfaces with different exposure times to methyl methacrylate UV photografting.

Figure 5.- Topographyc 3D-AFM graphs of polypropylene surface with different exposure times to methyl methacrylate UV photografting. 


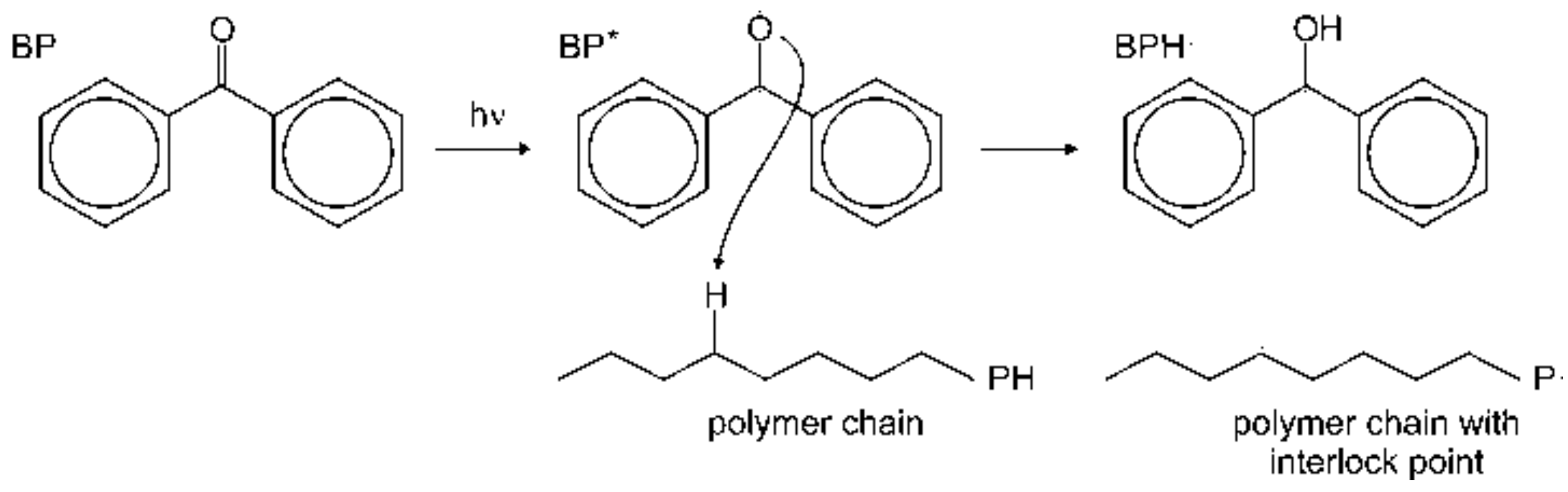


(A)

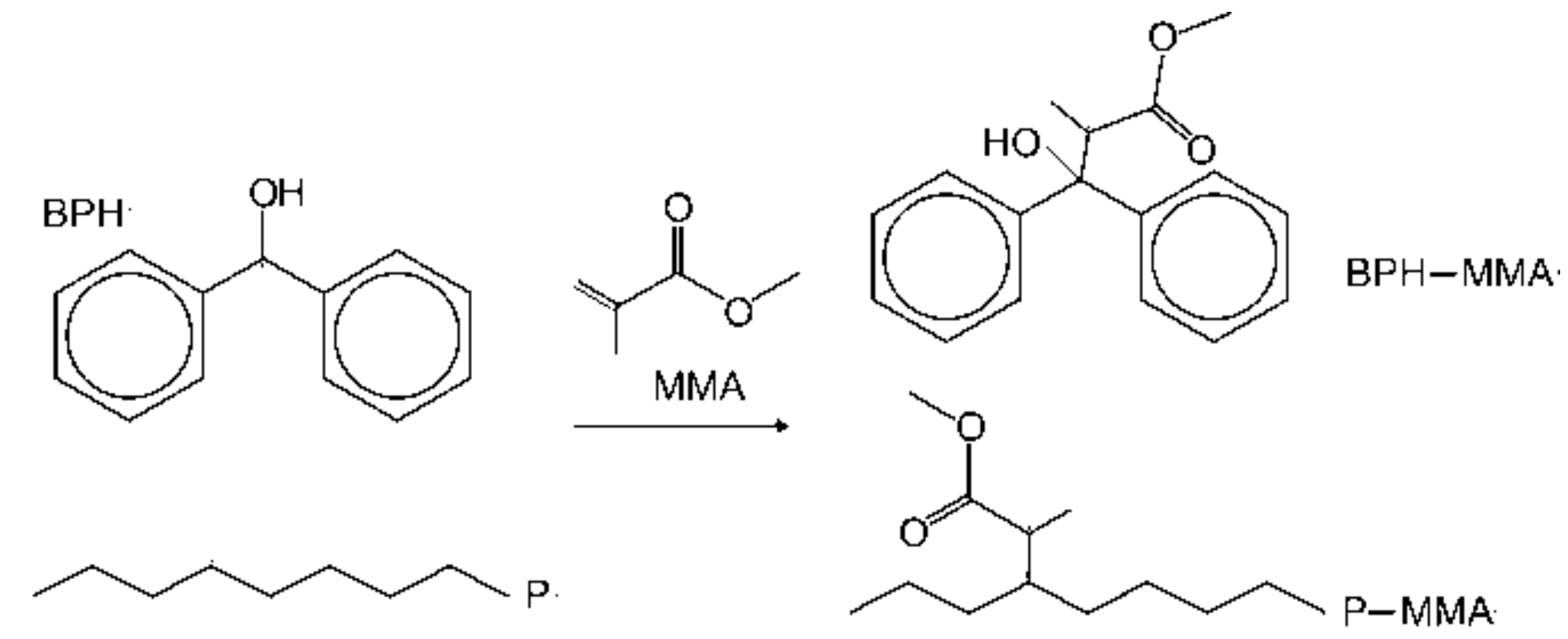

$$
\mathrm{BPH}-\mathrm{MMA} \stackrel{m \text { MMA }}{\longrightarrow} \mathrm{BPH}-\mathrm{MMA}_{m}-\mathrm{MMA}
$$

(B)

$$
\mathrm{P}-\mathrm{MMA} \quad \stackrel{n \text { MMA }}{\longrightarrow} \mathrm{P}-\mathrm{MMA}_{n}-\mathrm{MMA}
$$




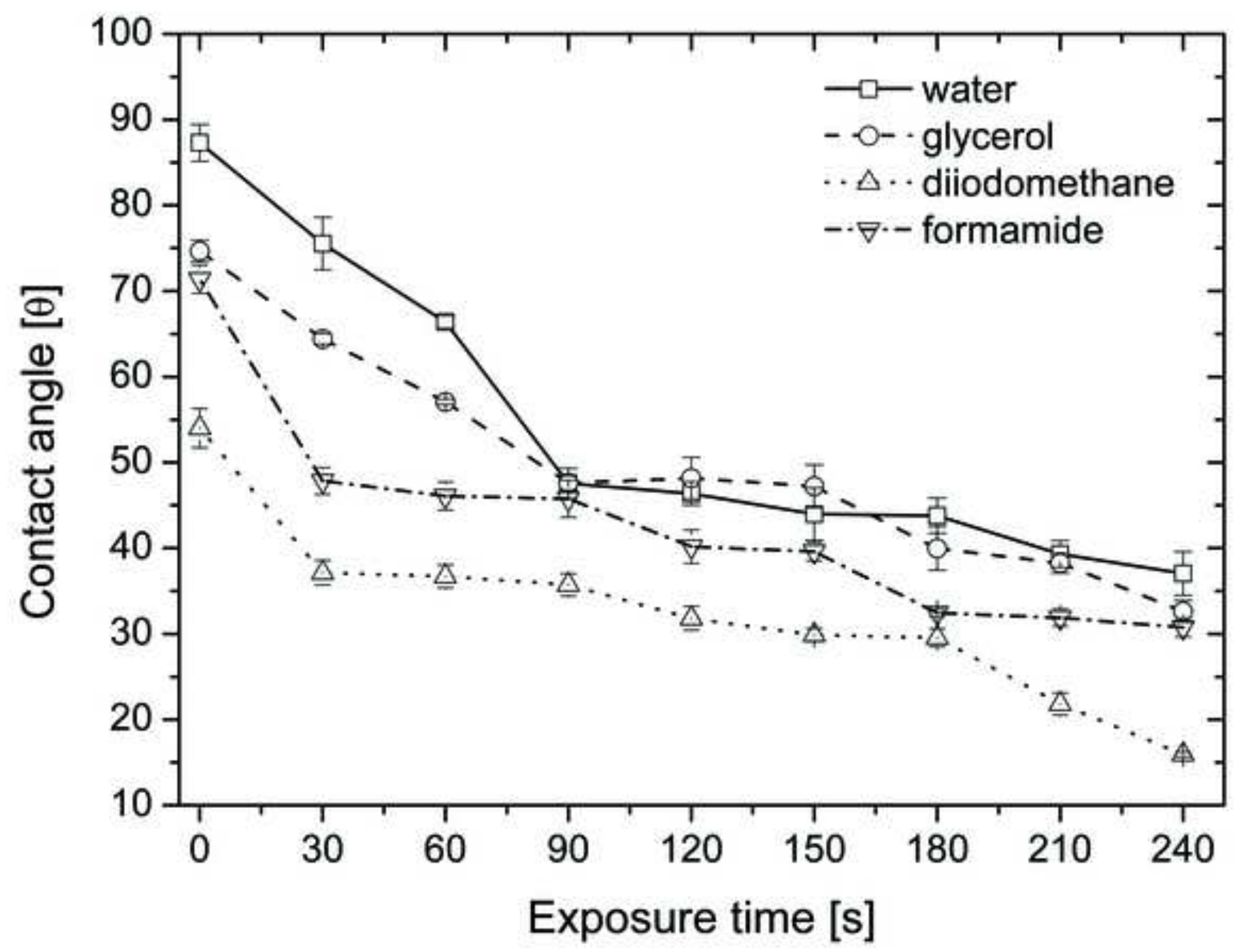




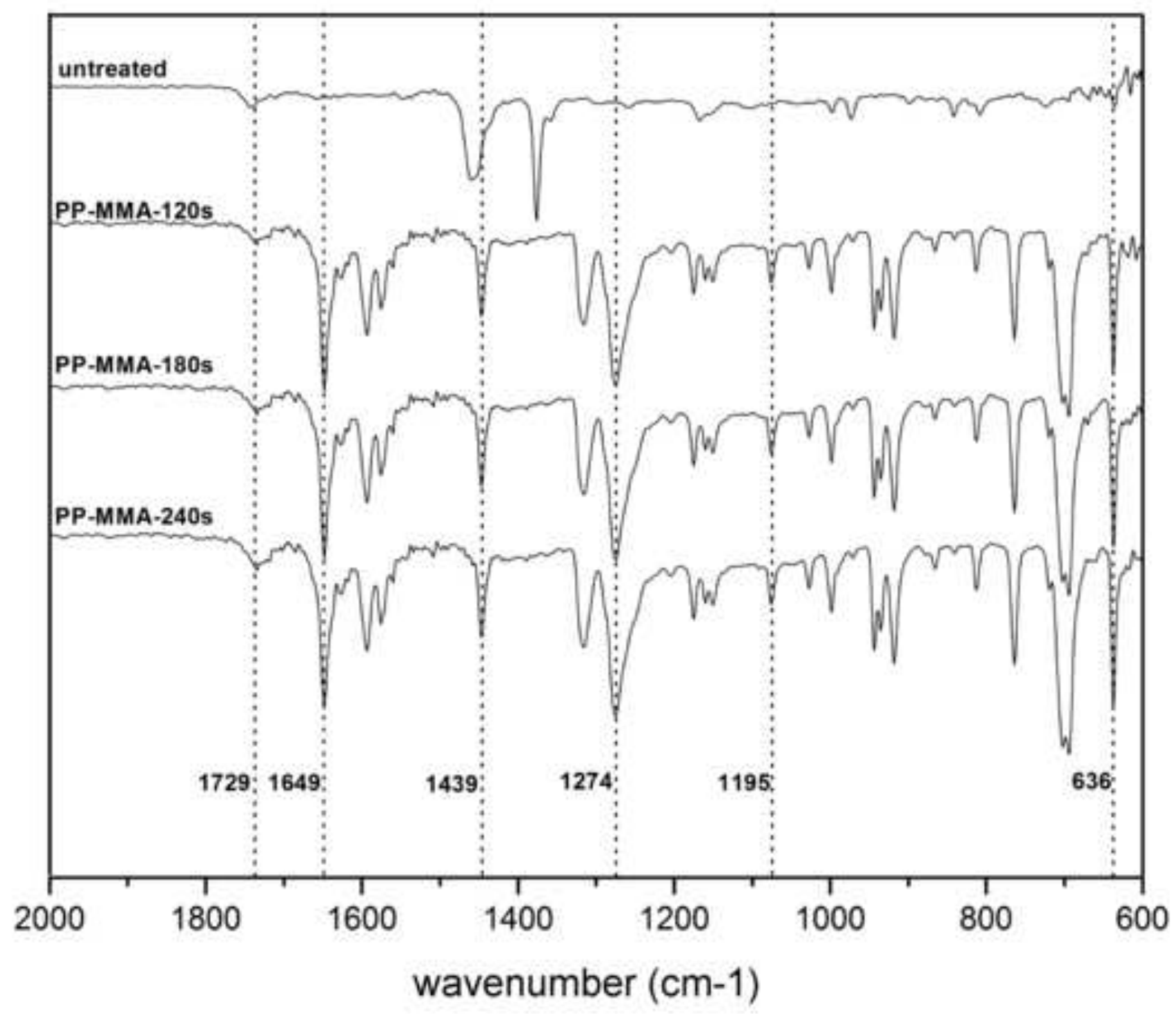



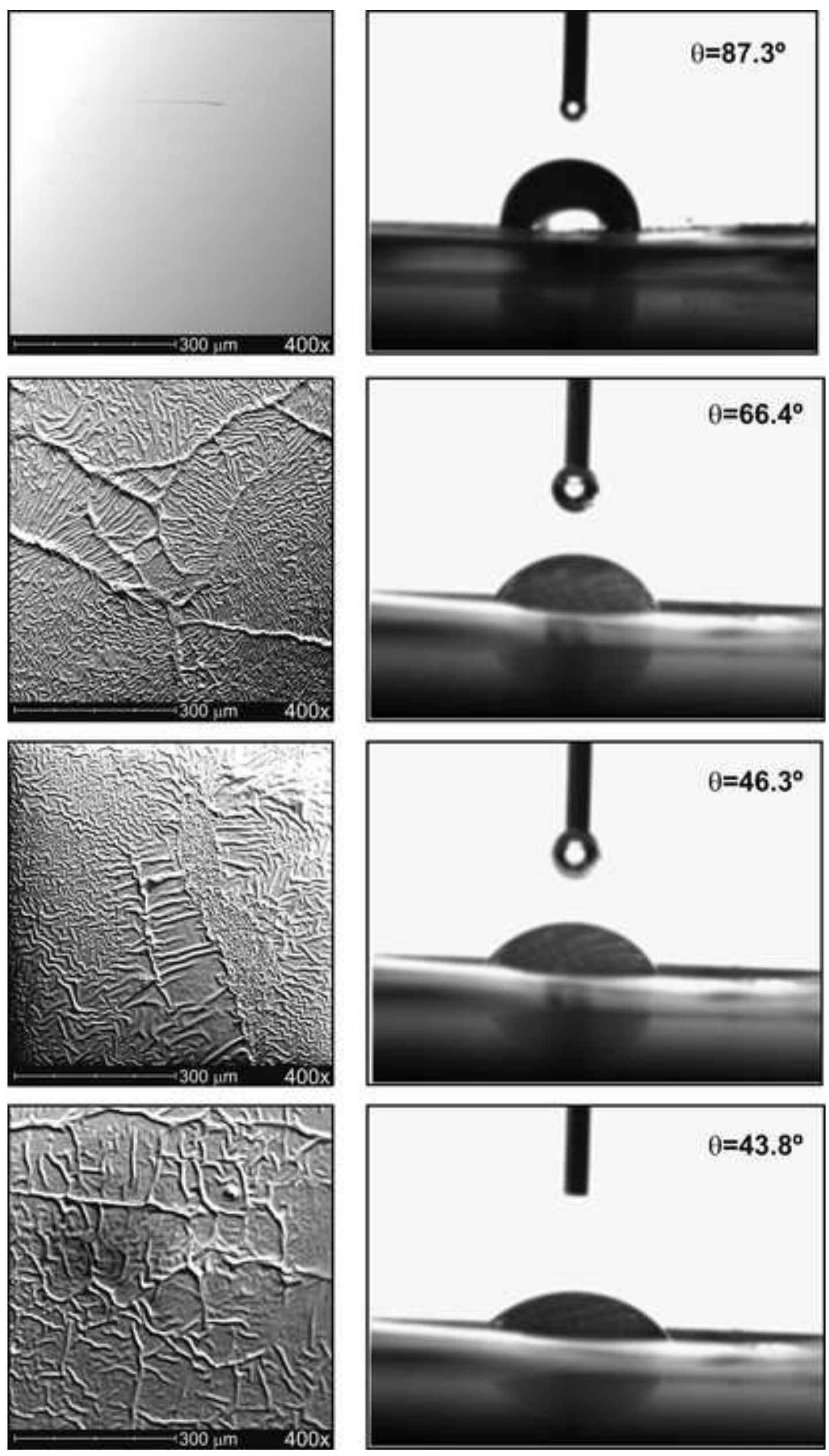


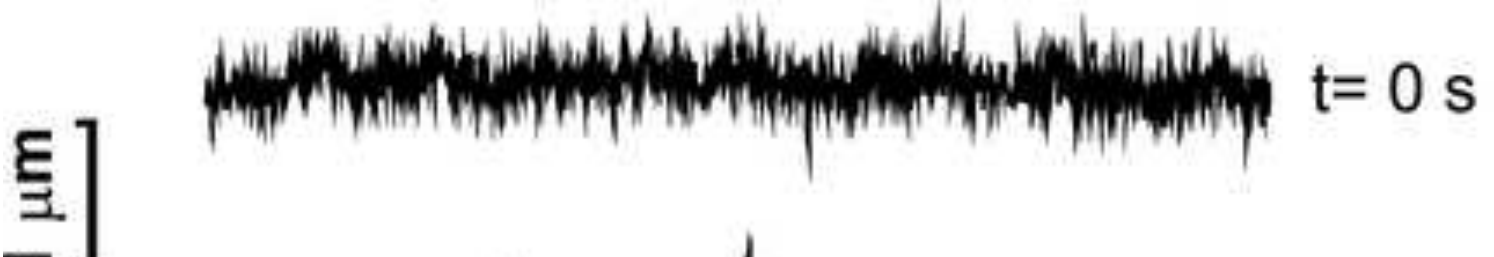 \\ -}

¿

N
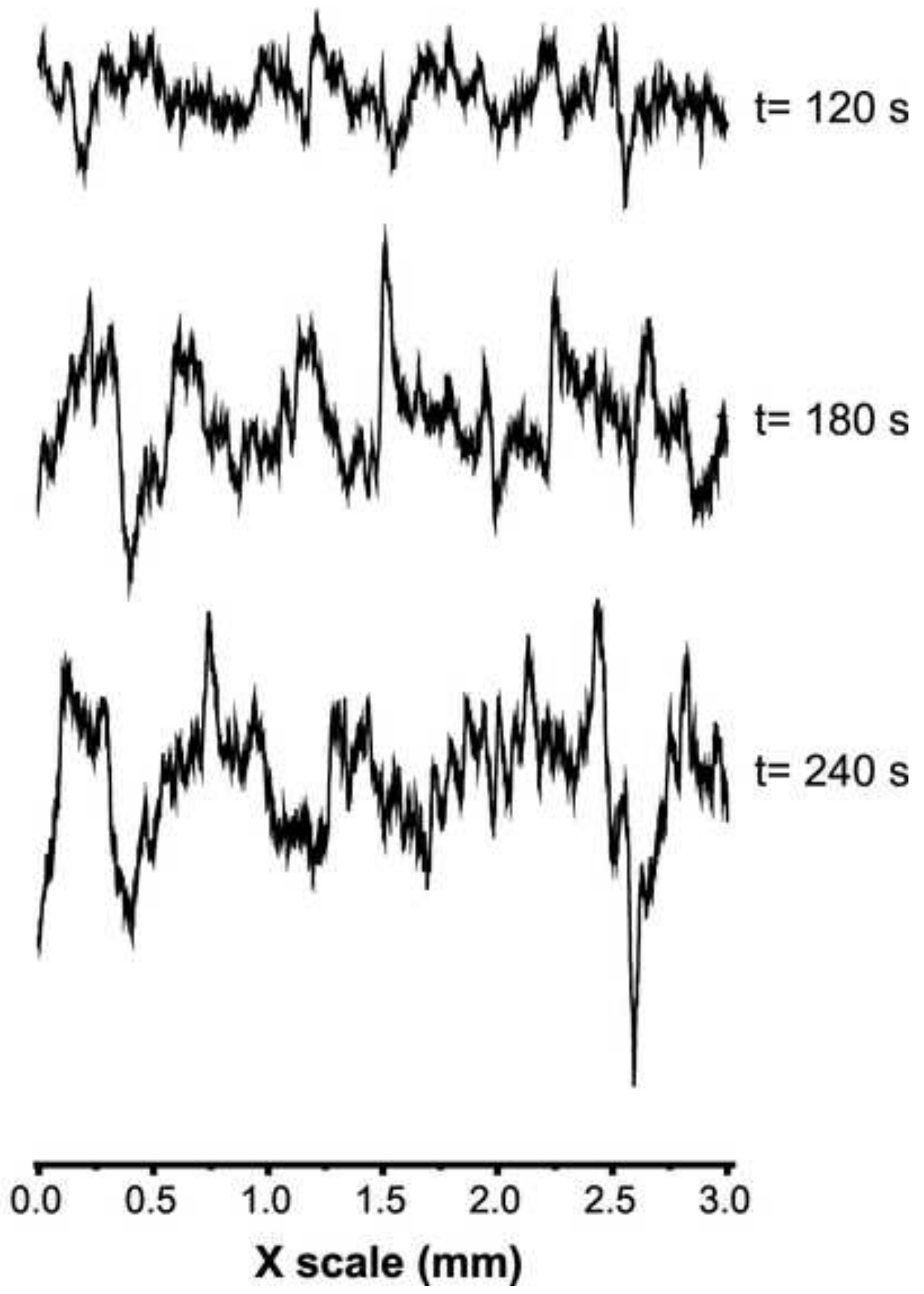
a)
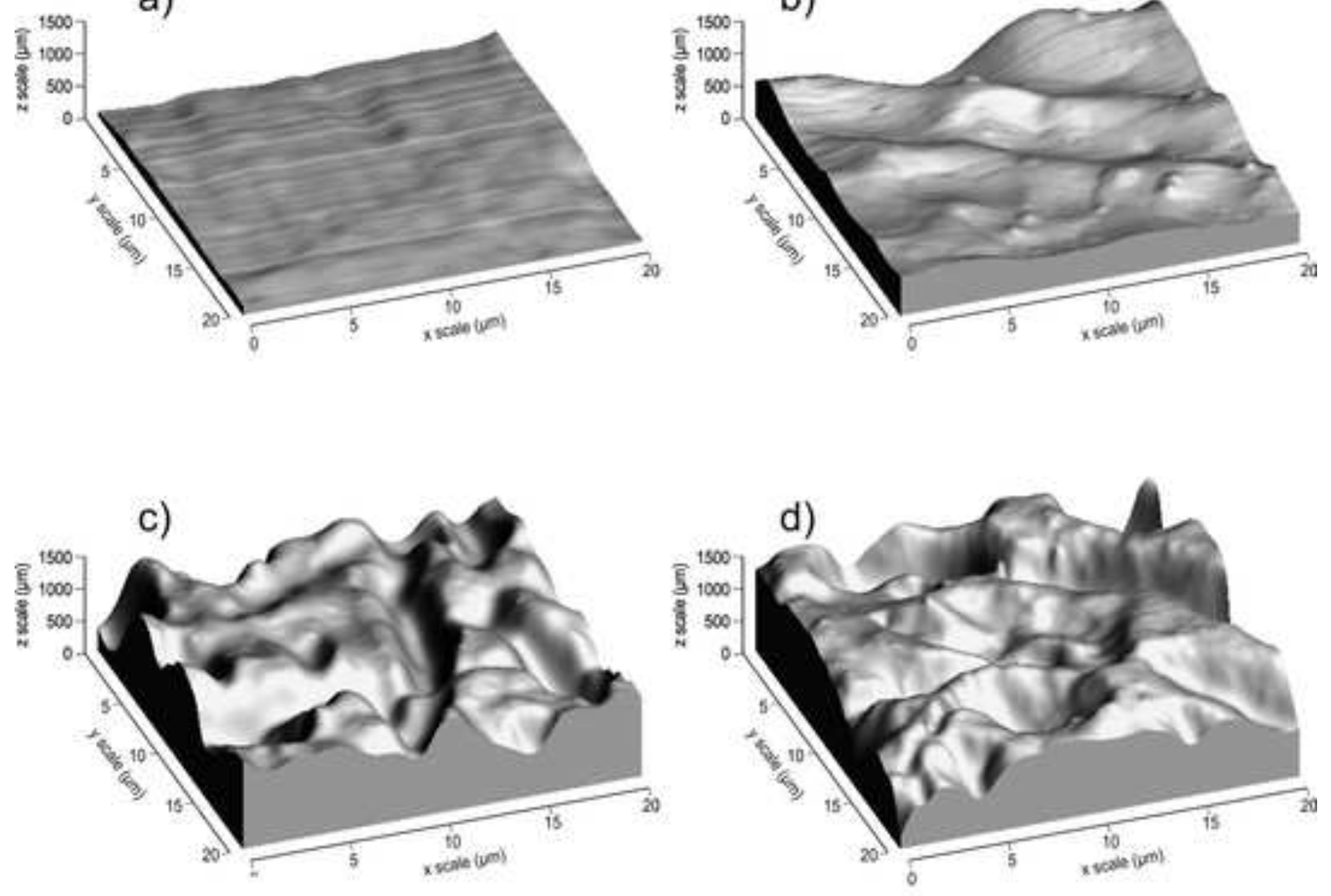

b)

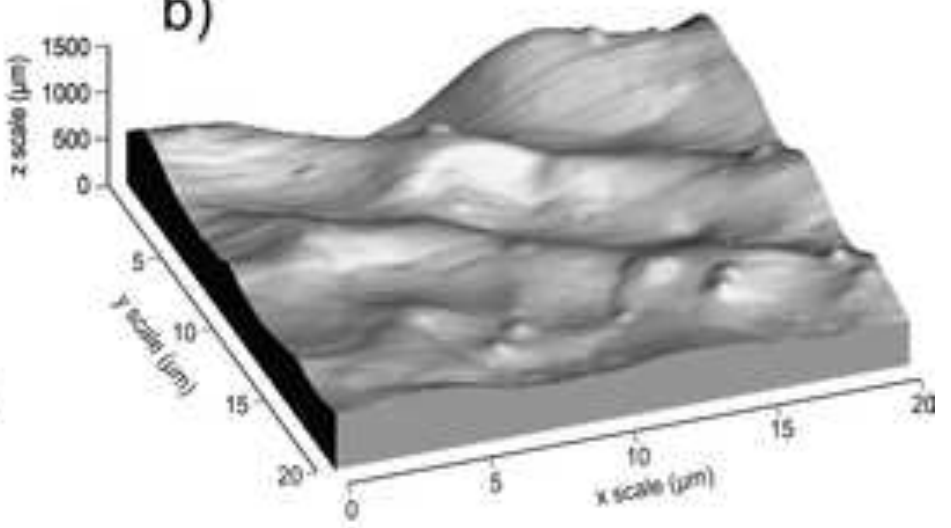

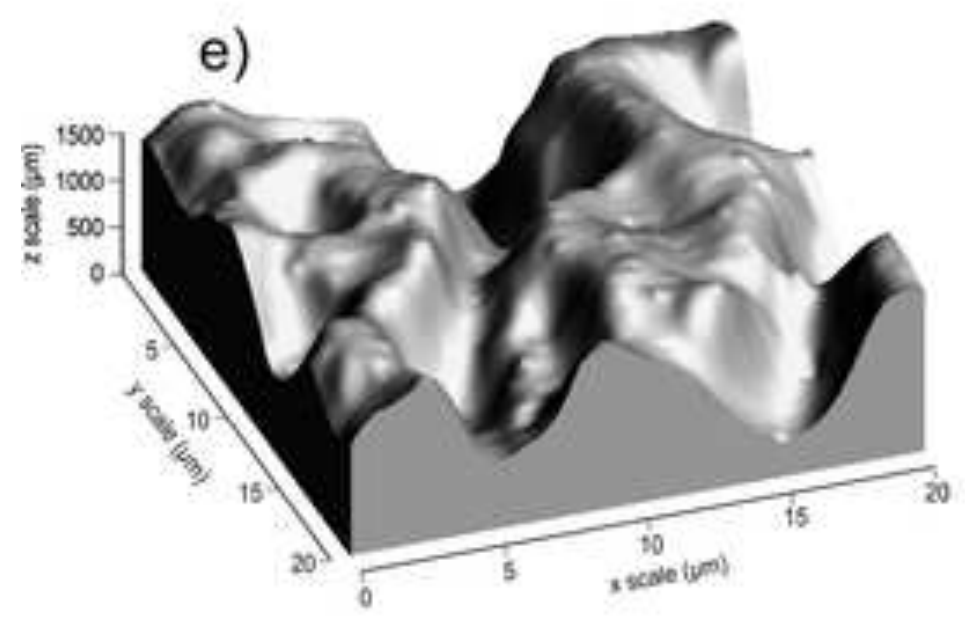


Table 1.-

\begin{tabular}{|c|c|c|c|}
\hline Exposure time [s] & $\gamma_{\mathbf{S}}\left[\mathbf{m} \mathbf{J ~ m}^{-\mathbf{2}}\right]$ & $\gamma_{\mathbf{S}}{ }^{\mathbf{p}}\left[\mathbf{m} \mathbf{J ~ m}^{-2}\right]$ & $\gamma_{\mathbf{S}}{ }^{\mathbf{d}}\left[\mathbf{m} \mathbf{J} \mathbf{~ m}^{-2}\right]$ \\
\hline 0 & 31.4 & 3.0 & 28.4 \\
\hline 30 & 42.2 & 5.5 & 36.6 \\
\hline 60 & 43.4 & 10.4 & 33.0 \\
\hline 90 & 48.7 & 23.0 & 25.7 \\
\hline 120 & 49.9 & 22.2 & 27.7 \\
\hline 150 & 51.2 & 23.9 & 27.2 \\
\hline 180 & 53.6 & 24.3 & 29.3 \\
\hline 210 & 55.6 & 25.6 & 30.0 \\
\hline 240 & 57.5 & 26.2 & 31.3 \\
\hline
\end{tabular}


Table 2.-

\begin{tabular}{|c|c|c|}
\hline Exposure time $[\mathbf{s}]$ & $\mathbf{R a}[\boldsymbol{\mu m}]$ & $\mathbf{R z}[\boldsymbol{\mu m}]$ \\
\hline 0 & 0.11 & 0.89 \\
\hline 60 & 0.17 & 1.37 \\
\hline 120 & 0.31 & 2.98 \\
\hline 180 & 0.41 & 2.63 \\
\hline 240 & 0.53 & 3.36 \\
\hline
\end{tabular}


Table 3.-

\begin{tabular}{|c|c|c|}
\hline Exposure time [s] & Rms [nm] & Rmax [nm] \\
\hline 0 & 26.6 & 155.0 \\
\hline 60 & 99.3 & 669.6 \\
\hline 120 & 179.1 & 1150.0 \\
\hline 180 & 265.9 & 1380.1 \\
\hline 240 & 310.1 & 1409.1 \\
\hline
\end{tabular}

